\title{
Postnatal development of subterranean habits in tuco-tucos Ctenomys talarum (Rodentia, Caviomorpha, Ctenomyidae)
}

\author{
Alejandra Isabel Echeverría ${ }^{1} \cdot$ Laura Marina Biondi $^{1,2} \cdot$ Federico Becerra $^{1,3}$. $^{2}$ \\ Aldo Iván Vassallo ${ }^{1}$
}

Received: 14 September 2015/Accepted: 18 November 2015

(C) Japan Ethological Society and Springer Japan 2015

\begin{abstract}
Postnatal development of subterranean habits was investigated in Los Talas' tuco-tuco Ctenomys talarum, a subterranean caviomorph rodent endemic from South America. Since in this species, some key morphofunctional traits related to scratch-digging behaviour-a form of underground progression-are already present during early ontogeny and develop progressively, we predicted that this behaviour expresses early during postanatal development and its performance enhances gradually from pups to adults. The process of acquisition of different behaviours associated to the construction of a burrow system was recorded in 11 individuals, each one coming from different litters, inside a terrarium filled with natural soil. We found that scratch-digging and burrowing behaviours expressed early during postnatal development, particularly, during lactancy. The digging of a "true burrow" clearly preceded the dispersal age, with a high inter-individual variability, from 18 (lactancy) to 47 (post-weaning) postnatal days. Pups could lose the soil using their foreclaws and remove the accumulated substrate using their
\end{abstract}

Alejandra Isabel Echeverría

aiechever@mdp.edu.ar

1 Grupo Morfología Funcional y Comportamiento, Instituto de Investigaciones Marinas y Costeras, Universidad Nacional de Mar del Plata, Consejo Nacional de Investigaciones Científicas y Técnicas, Deán Funes 3250, 2do. Piso, 7600 Mar del Plata, Argentina

2 Grupo Vertebrados, Instituto de Investigaciones Marinas y Costeras, Universidad Nacional de Mar del Plata, Consejo Nacional de Investigaciones Científicas y Técnicas, Deán Funes 3250, 3er. piso, 7600 Mar del Plata, Argentina

3 Max Planck Weizmann Center for Integrative Archaeology and Anthropology, Max Planck Institute for Evolutionary Anthropology, Deutscher Platz 6, 04103 Leipzig, Germany hindfeet as adults do. During lactancy individuals could construct a simple burrow to shelter, and first burrow construction occurred in the absence of either a burrowing demonstrator or an early subterranean environment (a natal burrow). However, certain features of the complex burrow system that characterize this species, such as lateral branches and nest chamber, just appeared after weaning. The time elapsed until animals started to dig and the time dedicated to underground activities varied with age, decreasing and increasing, respectively. In sum, our results show that-in C. talarum-immature digging behaviour gets expressed early during ontogeny, and develops progressively. The role of the early ability to build its own burrow and its possible function influencing the development of musculoskeletal traits and on efficiency for such conduct is discussed.

Keywords Postnatal ontogeny $\cdot$ Scratch-digging behaviour Subterranean rodents $\cdot$ Tuco-tucos

\section{Introduction}

For altricial animals, the initial phase in the ontogeny represents a stage of great vulnerability because younglings have to learn and refine survival and reproductive skills (Kirkton and Harrison 2006). Thus, investigating behavioural changes during an organism's development may provide insights into both the evolution of these behaviours and the differential ecology of various life stages (Stamps 2003). For small rodents, running and hiding are the main strategies to protect themselves from predators and burrows offer an excellent protection against most of them (Trillmich et al. 2003). On the other hand, digging (i.e., to breakup and remove the soil) and burrowing (i.e., to hide in 
burrows, to construct by tunnelling or to progress by or as if by digging) are common behaviours in many mammals, particularly in arid and semi-arid ecosystems (Nevo 1999; Whitford and Kay 1999). Moreover, the possession of a burrow with stable temperatures underground is especially critical for surviving in zones with great temperature fluctuations on the ground surface (Kinlaw 1999). For mammals that evolved to live underground, burrows play an important role in their interactions with the environment (Reig et al. 1990; Lacey et al. 2000), since they serve a number of purposes (e.g., thermoregulation, procurement and storage of foods, facilitation of social interactions and mating; see for examples, Fleming and Brown 1975; Ellison 1995; Ebensperger and Blumstein 2006). Accordingly, a subterranean lifestyle has become advantageous for small mammals in different phylogenetic lineages, not only because it provides a stable environment but also a shelter against predators (Antinuchi et al. 2007; Zelová et al. 2010)

Caviomorph rodents (Rodentia, Hystricognathi) represent one of the most diverse clades of rodents in terms of ecology, life history, body size, and locomotor habits (Mares and Ojeda 1982; Vassallo and Antenucci 2015). For example, the Superfamily Octodontoidea includes aquatic, arboreal, terrestrial, fossorial, and completely subterranean species with wide-ranging climbing and digging specializations (Morgan 2009; and references therein). Particularly, echimyids (spiny rats) and ctenomyids (tuco-tucos) are the most diverse families of South American caviomorphs (Parada et al. 2011; Fabre et al. 2013). Ctenomys, the only living genus of the family Ctenomyidae, is characterized by a high species richness ( $\sim 60$ recognized living species; Parada et al. 2011). These species occur over a wide geographical and environmental range, nevertheless they all share adaptations to terrestrial and underground activity (Camín et al. 1995). Los Talas' tuco-tuco ( $C$. talarum Thomas, 1898) inhabits dunes and interdunes at Buenos Aires Province (Argentina) and spends most of its life within plugged burrows (Reig et al. 1990), located parallel to soil surface (Busch et al. 1989; Antinuchi and Busch 1992). At the morphological level, adult tuco-tucos have a robust digging apparatus (forelimbs and skull), which is specially adapted for loosening and transporting the soil (Fernández et al. 2000; Mora et al. 2003; Morgan and Verzi 2006; Verzi 2008). Vassallo (1998) found that, when confronted with sandy and friable soils, these tucotucos exclusively use their forelimbs-scratch-digging- to break down the soil. Conversely, when it is confronted with harder and clayey soils, they behaved as a scratch- and chisel-tooth digger, using also the incisors to dig. This species builds extensive and elaborated tunnel systems with many feeding openings (Antinuchi and Busch 1992), which are characterized by a branching structure (main axial tunnel representing $48 \%$ of the total length, a single nest, and a variable number of lateral blind and foraging tunnels; Antinuchi and Busch 1992). Although increasing evidence suggests that several complex behaviours in higher vertebrates are socially transmitted from mother to offspring, it was shown that vertical social transmission is not essential for the development of subterranean habits in C. talarum (Vassallo 2006). This rodent is solitary and highly territorial, both sexes and all ages displaying a low vagility, whose individuals do not share burrows except for females and their offspring (up until the time of dispersing) or at the moment when mating occurs (Busch et al. 1989). Nestlings stay inside the natal burrow during a $\sim 2$ months period (Zenuto et al. 2002a), which probably determines the species-typical early environmental conditions. They show a long gestation period [95 days; (Zenuto et al. 2002b)], and females raise pups in isolation (i.e., without any male or conspecific cooperation), which are rather altricial with respect to the developmental stage at birth (Zenuto et al. 2002a; Cutrera et al. 2003).

Although there are studies on digging behaviour of adult tuco-tucos (Camín et al. 1995; Giannoni et al. 1996; Vassallo 1998), the literature contains little information concerning its postnatal development. Our goal was to investigate the postnatal development of subterranean habits in $C$. talarum under semi-natural conditions by analysing: (i) the first appearance and time course of changes in the ability to break down and remove the soil and associated behaviours, (ii) the time course of changes in the architecture of the excavated burrow system. Digging behaviour is a highly specialized and derived locomotor behaviour (Lessa et al. 2008) by which animals progress underground by breaking down and removing the soil. Evidence from postnatal development analyses of different modes of locomotion in rodents (see Eilam 1997) showed that those species with more specialized locomotor behaviours (e.g., asymmetrical gaits: bound, gallop and bipedal walk) exhibit them late during ontogeny, compared to more generalized modes (e.g., symmetrical gaits: lateral walk and trot). This fact is partly related to the acquisition of certain morphological features (for example, proportionally longer hindlimbs in jumping species; see Eilam 1997). However, Echeverría et al. (2014) showed that-in C. talarum - some morphological adaptations to scratchdigging are already present during early postnatal ontogeny-suggesting that they are prenatally shaped-and develop progressively. Particularly, these authors have shown that the olecranon increasingly elongate, suggesting a gradual enhancement in the scratch-digging performance due to an improvement in the mechanical advantage of forearm extensors. According to these evidences, we hypothesized that the expression of the scratch-digging behaviour - which is related to fossoriality - is correlated 
with the development of morphofunctional characters in $C$. talarum (see Echeverría et al. 2014). Thus, we predicted that (1) scratch-digging behaviour emerge early during ontogeny, after the onset of more basic rodent locomotor behaviours (see Eilam 1997), and (2) the performance of scratch-digging behaviour enhance according to the developmental level of specific musculoskeletal features, needed to exert significant forces to break down and transport the soil (see Echeverría et al. 2014).

\section{Materials and methods}

\section{Subjects and housing}

Adult $C$. talarum (pregnant females, $N=11$ ) were collected at Mar de Cobo, Buenos Aires Province, Argentina $\left(37^{\circ} 45^{\prime} \mathrm{S}\right.$, $\left.57^{\circ} 56^{\prime} \mathrm{W}\right)$, using plastic live traps located in burrow openings with freshly excavated earth. Captures were carried out during June-January 2006 (i.e., the breeding season; Malizia and Busch 1991). They were housed in plastic boxes $(42 \times 34 \times 26 \mathrm{~cm})$ with wood shavings as bedding and, after giving birth, they shared their nest boxes with their offspring. Relative ambient humidity ranged from 50 to $70 \%$, temperature was automatically controlled $\left(24 \pm 1{ }^{\circ} \mathrm{C}\right)$ and light/dark cycle set as 12:12-h. Since $C$. talarum do not drink free water, it was not provided.

\section{Observational procedures}

During the first 15 postnatal days, the general behaviour of pups was registered for $\sim 5$ min (three times per day, observations occurred between 10.00-11.00, 14.00-15.00 and 16.00-17.00 h) inside their nest boxes and in presence of their mother. If animals were resting, the observational session was repeated afterwards. On the other hand, to describe ontogenetic changes during the acquisition of subterranean habits under seminatural conditions, we randomly chose one individual per litter $(N=11)$ and videorecorded its behaviour inside a terrarium during $45 \mathrm{~min}$ every 5 days, until they were about 2 months old. These observations started from the postnatal day 15-age at which the animals begin to thermoregulate by themselves (Zenuto et al. 2002a; Cutrera et al. 2003). They were allowed to acclimate to handling conditions for at least 7 days prior to participate in these observational sessions inside the terrarium; i.e., when they were $\sim 7$ days old. For this purpose, they were removed from their nest boxes during 5 min per day and gently manipulated inside a clean transparent plastic box. According to Conour et al. (2006), the stress of transporting and placing the animals into a new environment mandate the need for a period of stabilization and acclimation (i.e., "recovery" period), so the stress responses can be minimized. Furthermore, these authors remarked that acclimation and stabilization are important to prevent the overwhelming animal's normal coping mechanisms, which maintain homeostasis and minimize animal distress. It is also well known that animals habituated to a handler or which are gentled in early life show less handling stress in later life and react only to the particular experimental stimuli used in the study (Tuli et al. 1995; and references therein).

Observational sessions were video-recorded using a JVC video recorder (model GR-DVL 505) and the terrarium consisted of a white PVC box $(60 \times 40 \times 35 \mathrm{~cm})$ with rounded corners and opened top, filled with natural soil. The video-recorder was placed above the terrarium, close enough to cover its entire superficial area and register behavioural activities. After placing the animal inside the terrarium, the observer (AIE) left the room slowly and avoiding to making noises. Natural soil was used because soil type may affect the tunnel extension and the architecture of the burrow system (Heth 1989; Antinuchi and Busch 1992). The substrate used was collected at the site at which pregnant females were captured, preserving its hardness, moisture and roots of natural grasses. At this site, average soil humidity and hardness were of $4.44 \pm 1.90 \%$ and $10.27 \pm 2.94 \mathrm{~kg} / \mathrm{cm}^{2}$, respectively (Cutrera et al. 2006). We included two grass patches-identical in areaof Bromus unioloides Kunth (bromegrass) and Panicum racemosum Spreng. (panicgrass)_both covering $40 \%$ of the surface. These grasses are present in the natural diet of C. talarum and they are among the most preferred ones (Comparatore et al. 1995; del Valle et al. 2001).

Before each observational session began, we included a fresh sample of soiled shavings from the nest box, containing faeces, urine and other body secretions from mother and siblings (i.e., familiar odors' sample), in glass Petri dishes (5 cm diameter) covered with wire mesh to prevent subjects from coming into direct contact with the sample. Disposable latex gloves were used during all procedures to minimize human scent transfer while handling odor samples. Overall, we used natural soil and plant cover to provide a seminatural environment, with natural shelter and food, and familiar odors were included to avoid stress effects during observational sessions. After concluding observations, females were released together with their offspring at the site of capture, at good physical condition.

\section{Behavioural variables}

We distinguished different behavioural acts directly linked to the burrowing activity in $C$. talarum and quantified them throughout postnatal development. Following previous studies (e.g., Malizia and Busch 1991; Zenuto et al. 2002b), age categories considered in this study were: lactation 
(pups; L: 1-35 days old), weaning (weanlings; W: 36-45 days old), post-weaning (post-weanlings; PW: 46-55 days old) and dispersal age (dispersers or juveniles; D: 56-65 days old). The following behavioural variables were included:

(a) General behaviour. Starting on postnatal day 1, the development of locomotor behaviour in a quadrupedal posture was recorded in the nest boxes, which were checked three times per day until the postnatal day 15. Furthermore, the mode of locomotion (sequence of steps) was evaluated by placing and video-recording four pups, coming from two additional litters, into a closed white PVC tube $(55 \mathrm{~cm}$ in length and $12 \mathrm{~cm}$ in diameter) with a glass floor $(45 \times 6 \mathrm{~cm})$. According to the steps' patterns during locomotion, we documented the apparition of locomotion modes following Eilam (1997). On the other hand, we explored ontogenetic changes in the time spent in three major behavioural categories: exploration (i.e., time dedicated to locomotion behaviour aboveground), digging activities (scratch-digging using the foreclaws), and foraging. The time spent performing these behaviours was compared by age as time budget.

(b) Rearing behaviour. We recorded the appearance and possible ontogenetic changes in rearing behaviour, a body posture in which animals stand-up while scanning the surrounding habitat. Within subterranean mammals, this behaviour was only documented in the genus Ctenomys (e.g. Hickman 1985).

(c) Scratch-digging behaviour. We distinguished two behaviours which are directly linked to the typical digging activity in $C$. talarum namely: soil removal and digging. Soil removal involved a superficial translocation in small volumes $\left(<400 \mathrm{~cm}^{3}\right)$ by means of gently movements of the foreclaws on the substrate, which implies drawing (i.e., to move after or toward one by applying continuous force) the claws downward toward, or under, the body. This temporary activity resulted in the formation of small cavities. Oppositely, digging was a sustained activity which involved vigorous scraping movements which included the extending of the forefeet into the ground and then breaking up the soil, moving larger volumes $\left(\gg 400 \mathrm{~cm}^{3}\right)$ to construct tunnels and chambers. After these activities were distinguished, we considered the following descriptive variables:

(i) Latency, i.e., time elapsed between the positioning of the test animal in the terrarium and its first soil removal or digging. (ii) Time dedicated to soil removal (TR) and digging (TD) during each observational session.

(d) Burrow architecture. We established different levels of burrow complexity according to the main tunnel length $(\mathrm{cm})$, number of blind and foraging tunnels (i.e., lateral branches), burrow openings and nest presence. A completely closed tunnel of at least the animal's body length was considered a true burrow, and the simplest burrow structure consisted of a main tunnel without lateral branches or nest. The age at which individuals dug a true burrow for the first time was registered. Finally, we estimated the substrate volume that was removed during digging activities, specifically during tunnelling, and evaluated its variation during postnatal development.

\section{Statistical analysis}

To describe ontogenetic changes in subterranean habits of C. talarum we used generalized linear mixed models (GLMM) that incorporates both random and fixed variables (Crawley 2007). All variables except the rearing behaviour frequency and volume of removed substrate were transformed to proportions. In the case of time variables (latencies and time dedicated to a specific activity), we considered the ratio between raw data and the observational session time duration. For the volume of removed substrate, we used linear mixed-effects models (LMM) fitted by REML with the lme function of nlme package (Pinheiro et al. 2011). Finally, rearing behaviour frequencies were relativized to the duration of the observational session. In all models, we included individual identity as a random factor and postnatal days (continuous variable) and age classes (categorical variable, from L1 to D2; see $B e$ havioural variables above) as explanatory variables. The analysis was implemented using the glmmPQL function in the MASS package (Bates et al. 2011) within R version 2.5.1 (R Core Development Team 2012). As proportion was used in all variables, the analysis was performed using a binomial error structure with a logit link function (Pinheiro and Bates 2000; Crawley 2007). To analyse the maximum tunnel length that was excavated by individuals throughout postnatal development, this variable was $\log _{10^{-}}$ transformed to meet normality and homoscedasticity assumptions, and a linear mixed model was used. The lme function of nlme package (Pinheiro et al. 2011) was implemented to carry on this model. If an animal excavated more than one tunnel per observational session we included the length measure of the longest one. 


\section{Results}

\section{General behaviour}

All individuals showed a forward locomotion in a quadrupedal posture during early postnatal development (1-2 days). Neonates began to wander in a lateral sequence with their eyes closed, e.g., lateral walking — a mode of progression characterized by a symmetrical sequence: left hind foot, left forefoot, right hind foot, right forefootspecially after their mother stopped feeding them and moved away. This early locomotion was characterized by the absence of full weight-supported steps, which appeared at about 7 days old.

The analysis of time budget by age showed that pups and weanlings spent most of the time exploring their surroundings, and less time digging and foraging, in that order (Fig. 1; Table 1). Otherwise, post-weaning and dispersers dedicated more time to digging and exploration than foraging (Fig. 1; Table 1).

\section{Rearing behaviour}

This behaviour began between 18-to-42 postnatal days (mean $\pm \mathrm{SD}=29.0 \pm 7.5$ days), and its frequency varied with age (GLMM; $d f=21, t=3.23, p<0.01$; Fig. 2), Particularly, contrasts showed that this behaviour was increasingly common until the post-weaning age (GLMM; $\mathrm{L}$ vs. $\mathrm{W}: t=-3.23, p<0.01$; L vs. PW: $t=-5.39$, $p<0.0001$; W vs. PW: $t=-0.87, p<0.01$; Fig. 2), after which it decreased to values that did not differ significantly

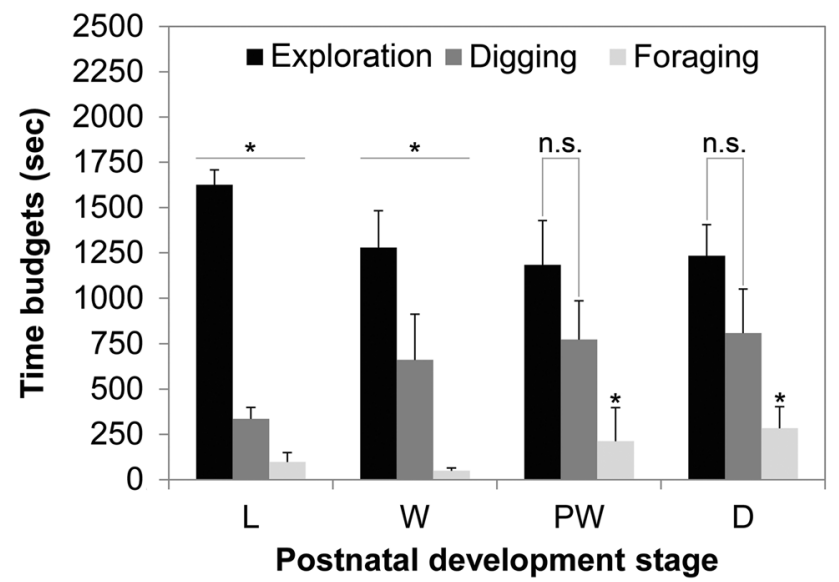

Fig. 1 Bar-plot (mean \pm SE) of time budgets by age category throughout Los Talas' tuco-tuco (Ctenomys talarum) postnatal development. Three general aboveground behaviours (exploring, digging and foraging) were considered. References: $L$ lactancy, $W$ weaning, $P W$ post-weaning and $D$ dispersal age. Contrasts' results after GLMM analyses are coded as: n.s. non-significant differences; and $* p<0.05$ to those observed in weanlings (GLMM; D vs. W: $t=0.22, p>0.05$; D vs. PW: $t=-0.65, p<0.05$; D vs. L: $t=1.57, p<0.01$; Fig. 2).

\section{Scratch-digging behaviour}

Pups did not stereotypically dig (i.e., compulsive digging in a wall or a corner), as it was observed in other rodents (e.g., Wiedenmayer 1997), neither at the nest box nor inside the terrarium. Rather, $80 \%, 13 \%$ and the remaining $7 \%$ of the pups scratched the substrate when they were confronted for the first, second and third time, respectively, with it in the terrarium (mean $\pm \mathrm{SD}$ age; $17.7 \pm 1.9$ days), alternating the use of their well-developed foreclaws during short periods with other typical behaviours (e.g., foraging, grooming, sleeping, exploration). Particularly, we observed that the initial response of some animals was to gently scratch-digging on the substrate while others committed to dig a tunnel (76 and $24 \%$ of the individuals, respectively). Scratch-digging was performed with foreclaws, resulting in small holes where animals sheltered. The digging of a true burrow clearly preceded the dispersal age and ranged from 18-to-47 (lactancy to post-weaning, respectively; mean $\pm \mathrm{SD}=30.4 \pm 8.9$ days; $\quad$ median $=27.0$ days $)$ postnatal days, age at which all of the animals under study excavated a tunnel of at least one body length.

Generalized linear mixed models showed that latencies to remove the soil (LR) and to dig a tunnel (LD) varied significantly in function to age (GLMM; LR: $d f=46$, $t=-2.59, \quad p<0.05$ and LD: $d f=46, \quad t=-2.92$, $p=0.01$; Fig. 3a, b). Particularly, contrasts analyses showed that LR and LD significantly decreased during last two stages (Fig. 3a, b, respectively; Table 2); i.e., postweanlings and dispersers showed lower latencies to remove than weanlings, and lower latencies to dig than pups and weanlings.

Regarding the time that individuals spent removing the soil (which resulted in the formation of small cavities), there was not significant differences across ages (GLMM: $d f=46, t=-0.49, p>0.05$, Fig. 4a). Conversely, the time dedicated to construct true burrows showed significant differences between ages (GLMM: $d f=46$, $t=4.25, p<0.001)$ where pups dedicated significantly less time than weanlings, post-weanlings and dispersers (Fig. 4b; Table 2). Even though the number of small holes excavated did not vary with age (GLMM: $d f=63$, $t=0.91, p>0.05)$, there was a clear variation in the soil volume that was excavated during tunnel digging between ages (GLMM: $d f=23, t=4.23, \quad p<0.001$ ) where weanlings excavated more substrate than pups but showed non-significant variations during later ages (Fig. 5a; Table 3). 
Table 1 Summary of fixed-factor, pairwise contrasts from GLMM analysis comparing three general behaviours (time budget) in terms of age category

\begin{tabular}{|c|c|c|c|c|c|c|c|c|c|c|c|c|}
\hline \multirow[t]{2}{*}{ Contrasts } & \multicolumn{3}{|c|}{ Lactancy } & \multicolumn{3}{|c|}{ Weaning } & \multicolumn{3}{|c|}{ Post-weaning } & \multicolumn{3}{|c|}{ Dispersal } \\
\hline & Value & $t$ & $p$ value & Value & $t$ & $p$ value & Value & $t$ & $p$ & Value & $t$ & $p$ value \\
\hline EXP vs. DIG & 2.22 & 7.12 & 0.000 & 1.02 & 2.24 & 0.026 & 0.66 & 1.22 & 0.224 & 0.68 & 1.40 & 0.162 \\
\hline FOR vs. DIG & -1.33 & -2.52 & 0.013 & -2.88 & -2.46 & 0.015 & -1.55 & -2.08 & 0.040 & -1.29 & -2.03 & 0.044 \\
\hline FOR vs. EXP & -3.55 & -7.24 & 0.000 & -3.90 & -3.37 & 0.001 & -2.22 & -2.88 & 0.004 & -1.97 & -3.17 & 0.002 \\
\hline
\end{tabular}

In each model, individual identity was included as a random factor. References: exploring (EXP), foraging (FOR) and digging activities (DIG)

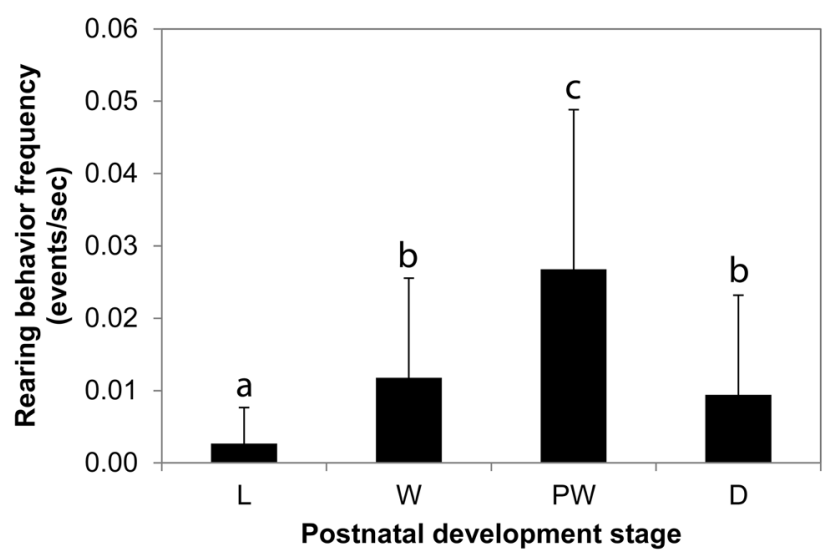

Fig. 2 Bar-plot (mean $\pm \mathrm{SE}$ ) of rearing behaviour frequency throughout the postnatal development of Ctenomys talarum. References as in Fig. 1. The same letter above the bar plots represents statistically similar means after contrasts analyses

\section{Burrow construction and architecture}

During burrow construction, forelimbs were used for loosening the soil while, starting from $20.7 \pm 2.1$ postnatal days (mean $\pm \mathrm{SD}$ ), hindlimbs simultaneously stroked the ground and transported substrate to the tunnel entrance via backward locomotion-described as inchworm locomotion in reverse by Hickman (1985). However, it was not until animals were close to weaning (31-to-36 days) that they expressed backward locomotion from the surface to the tunnel entrance. We observed that first burrows were simple, consisting of a main tunnel without other structures (mean \pm SD: $14.9 \pm 10.5 \mathrm{~cm}$ in length, $7.3 \pm 3.9 \mathrm{~cm}$ in depth and $4.4 \pm 1.3 \mathrm{~cm}$ in diameter), and tunnel length varied with age (GLMM: $d f=23, t=4.65, p<0.001$; Fig. 5b) finally increasing in length its design from day 31 . Post-weanlings built a more complex burrow system, which included a nest chamber and lateral branches (Fig. 6). Thus, starting from weaning age, burrows became longer in $85 \%$ and more complex in $30 \%$ of the individuals studied. Finally, contrasts confirmed that tunnel length increased significantly during weaning age, no differences between weanlings and post-weanlings were

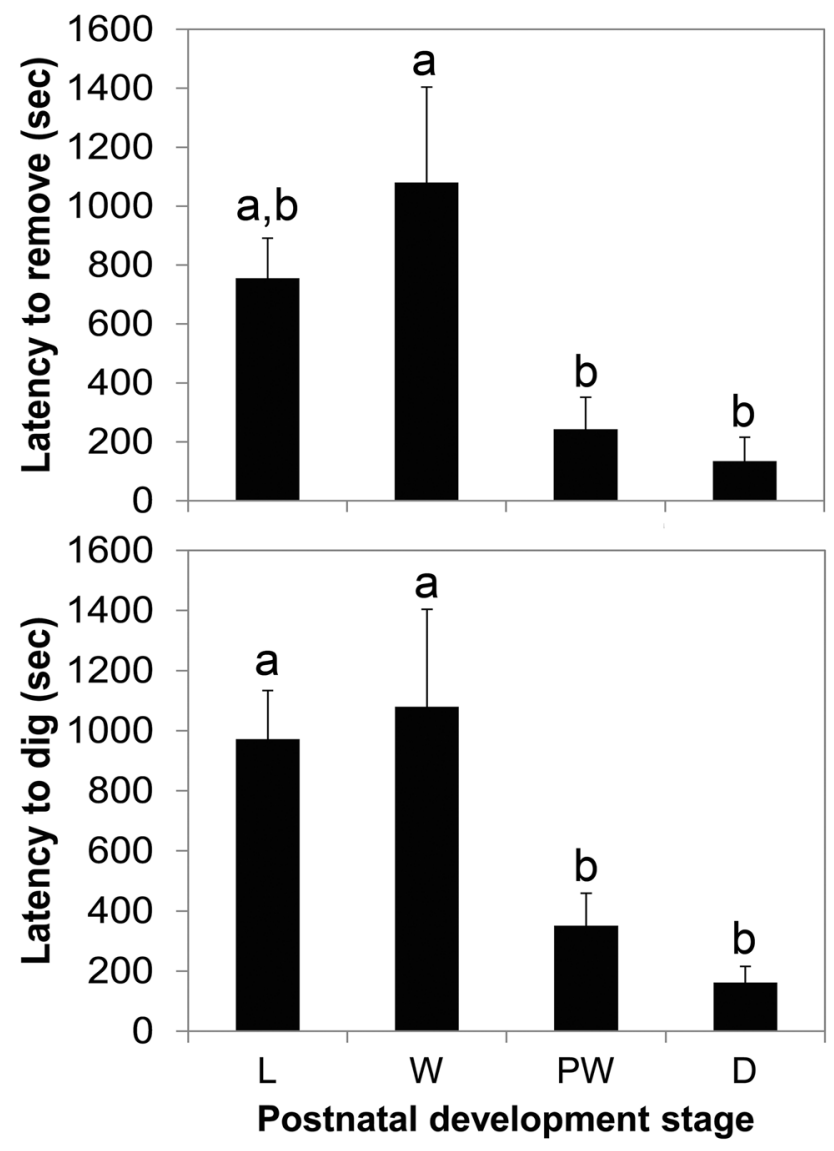

Fig. 3 Bar plots (mean \pm SE) of latency to remove the soil (a) and to dig (b) in Ctenomys talarum throughout its postnatal development (in seconds). References and differences as in Figs. 1 and 2, respectively

shown, and it only increased marginally during dispersal age (Fig. 5b; Table 3).

\section{Discussion}

This study was performed with the aim of assessing the ontogeny of the subterranean habit of $C$. talarum, emphasizing on the emergence and development of the burrowing 
Table 2 Summary of fixedfactor, pairwise contrasts from GLMM comparing latencies (latency to remove the soil and latency to dig), and time dedicated to tunnel digging in terms of age category (references as in Fig. 1)

\begin{tabular}{|c|c|c|c|c|c|c|c|c|c|}
\hline \multirow[t]{2}{*}{ Contrasts } & \multicolumn{3}{|c|}{ Latency to remove } & \multicolumn{3}{|c|}{ Latency to dig } & \multicolumn{3}{|c|}{ Time digging } \\
\hline & Value & $t$ & $p$ value & Value & $t$ & $p$ value & Value & $t$ & $p$ value \\
\hline L vs. W & -0.56 & -1.24 & 0.220 & -0.07 & -0.14 & 0.888 & -1.09 & -2.70 & 0.010 \\
\hline PW vs. W & -1.94 & -2.58 & 0.013 & -1.48 & -2.17 & 0.035 & 0.04 & 0.09 & 0.927 \\
\hline PW vs. L & -1.38 & -1.98 & 0.053 & -1.41 & -2.31 & 0.026 & 1.13 & 2.84 & 0.007 \\
\hline D vs. $L$ & -2.00 & -1.83 & 0.074 & -2.31 & -2.26 & 0.029 & 1.69 & 3.77 & 0.001 \\
\hline D vs. W & -2.56 & -2.26 & 0.028 & -2.38 & -2.24 & 0.030 & 0.60 & 1.26 & 0.214 \\
\hline D vs. PW & -0.62 & -0.50 & 0.622 & -0.90 & -0.79 & 0.433 & 0.56 & 1.18 & 0.245 \\
\hline
\end{tabular}

In each model, individual identity was included as a random factor
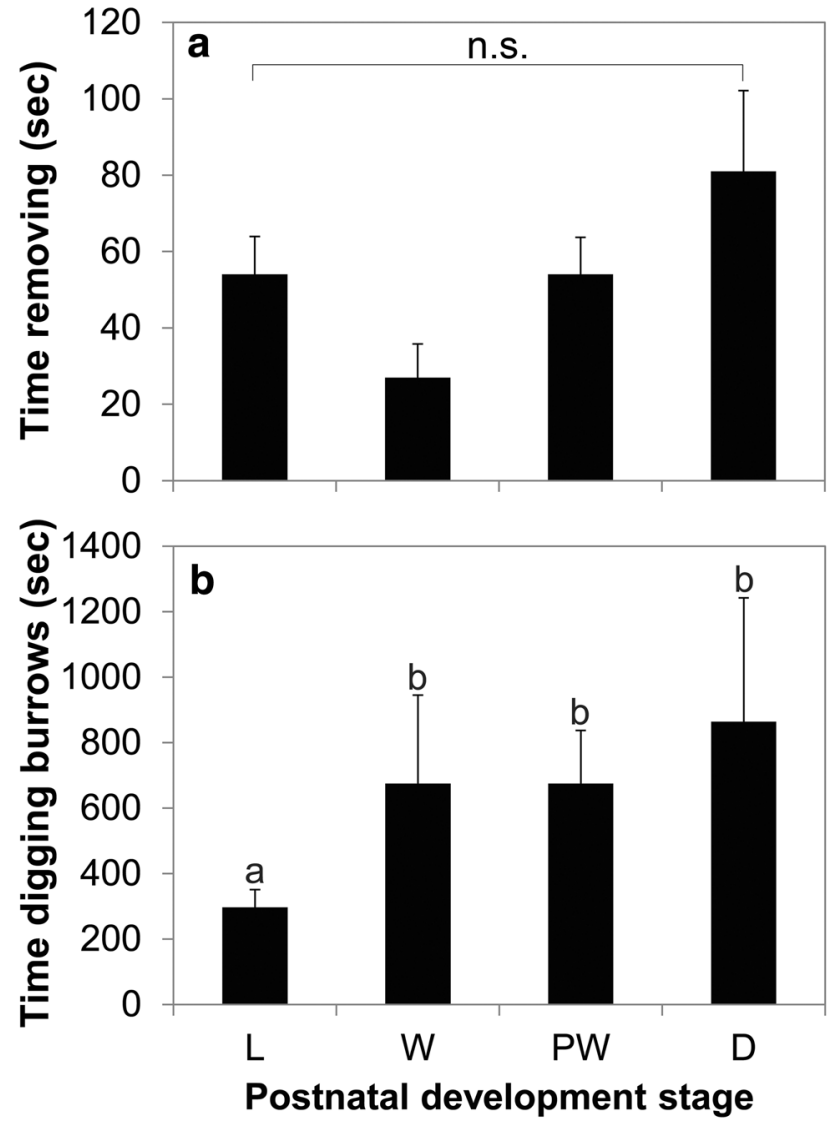

Fig. 4 Bar plots (mean \pm SE) of time dedicated to different burrowing activities: (a) soil removal (i.e. gently scratch-digging movements which resulted in small holes), and (b) digging (i.e., steadily scratch-digging movements, which resulted in tunnel construction) throughout the postnatal development of Ctenomys talarum. References and differences as in Figs. 1 and 2, respectively

behaviour. Due to the developmental stage at birth, $C$. talarum is conside-red as semi-altricial since the body of newborns is poorly furred, their eyes are still closed, and most likely cannot regulate their body temperature until they are 15 days old (Cutrera et al. 2003). However, they are relatively mobile and locomote immediately after birth through one of the more ancestral forms of terrestrial
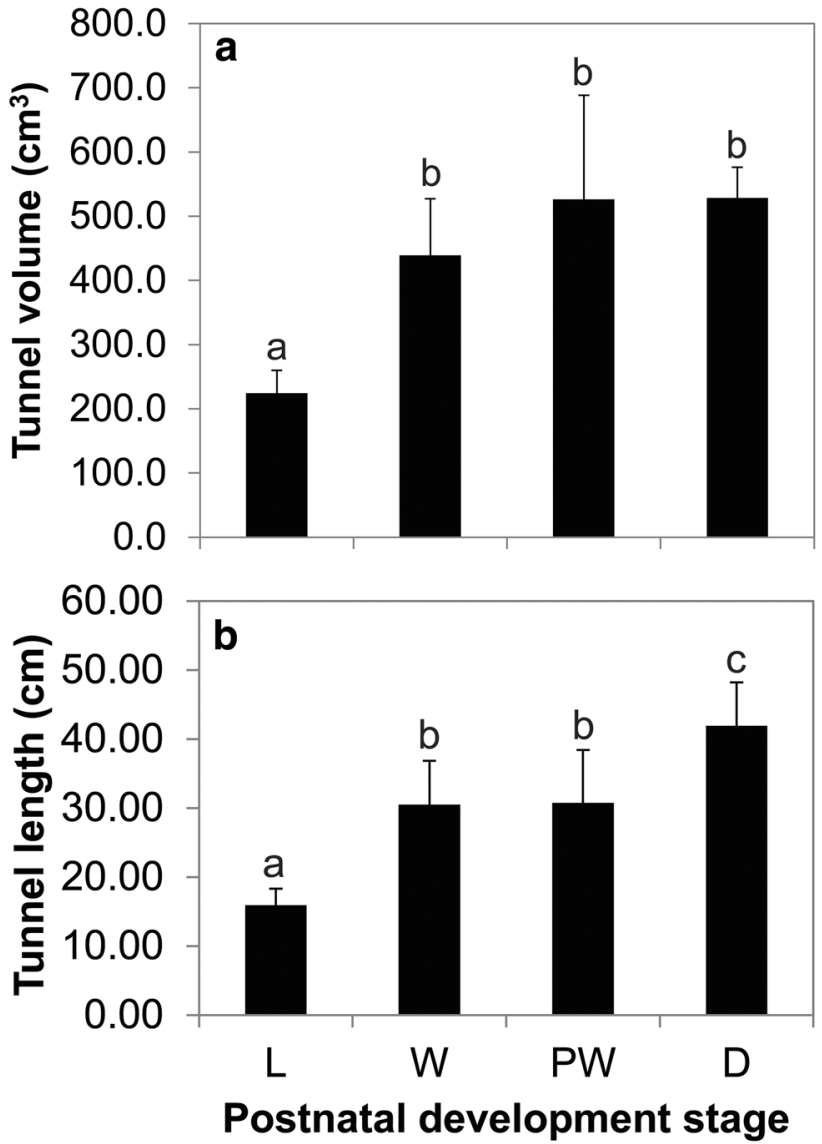

Fig. 5 Bar plots (mean \pm SE) of (a) the total volume of excavated soil (in $\mathrm{cm}^{3}$ ), and (b) the tunnel length built throughout the postnatal development of Ctenomys talarum. References and differences as in Figs. 1 and 2, respectively

quadruped locomotion; i.e. the lateral walk, despite steps are not full weight-supported. In spite of their relatively immature stage at birth, the main finding of this study is that scratch-digging behaviour expresses early during postnatal development. Thus, most of $C$. talarum pups (captive born and reared by their mother under seminatural conditions) are capable to start burrowing when they are confronted for the first time to the soil typically inhabited 
by this species. The progression by digging has particular requirements related to the ability of exerting significant external forces to loosen, remove and breaking down the

Table 3 Summary of fixed-factor, pairwise contrasts from GLMM comparing the tunnel length and the excavated soil volume by Ctenomys talarum across ages (references as in Fig. 1)

\begin{tabular}{|c|c|c|c|c|c|c|}
\hline \multirow[t]{2}{*}{ Age contrasts } & \multicolumn{3}{|c|}{ Tunnel length (cm.) } & \multicolumn{3}{|c|}{ Volume $\left(\mathrm{cm}^{3}\right)$} \\
\hline & Value & $t$ & $p$ value & Value & $t$ & $p$ value \\
\hline L vs. D & -1.19 & -5.27 & 0.000 & -1.10 & -4.49 & 0.000 \\
\hline PW vs. D & -0.45 & -2.08 & 0.050 & 1.16 & 5.39 & 0.000 \\
\hline W vs. D & -0.43 & -2.08 & 0.050 & -0.61 & -1.96 & 0.054 \\
\hline PW vs. L & 0.74 & 3.64 & 0.002 & 2.26 & 10.21 & 0.000 \\
\hline W vs. $\mathrm{L}$ & 0.76 & 4.02 & 0.001 & 0.49 & 1.57 & 0.122 \\
\hline W vs. PW & 0.02 & 0.10 & 0.919 & -1.77 & -6.09 & 0.000 \\
\hline
\end{tabular}

In each model, individual identity was included as a random factor substrate, and long bones must be capable of supporting the stress produced by muscle action and substrate's reaction forces (e.g., Hildebrand 1985). In this study we observed that, as the animals mature, the digging behaviour and burrow construction do so as well. Particularly, the motivation to engage in burrow construction increase significantly after weaning-reflected by differences in latency values-when animals start to devote more time to this activity. Accordingly, morphological evidence shows that some scratch-digging specializations are already present in C. talarum newborns and pups, which suggests that they are peri- or prenatally shaped, and other traits develop progressively. Specially, when compared to juveniles and adults, pups are characterized by an incipient olecranon process (ulna), relatively wide epicondyles, relatively distal deltoid process (humerus) and short and massive long bones in their forelimb (Echeverría et al. 2014). Furthermore, during early stages most of the morphological traits
Fig. 6 Some examples of burrows' designs observed in this study throughout the postnatal development of Ctenomys talarum
Lactancy age I pups
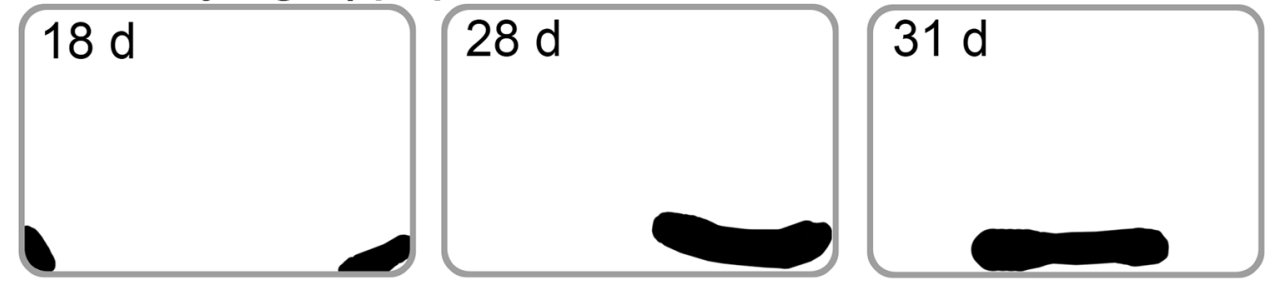

Weaning | weanlings
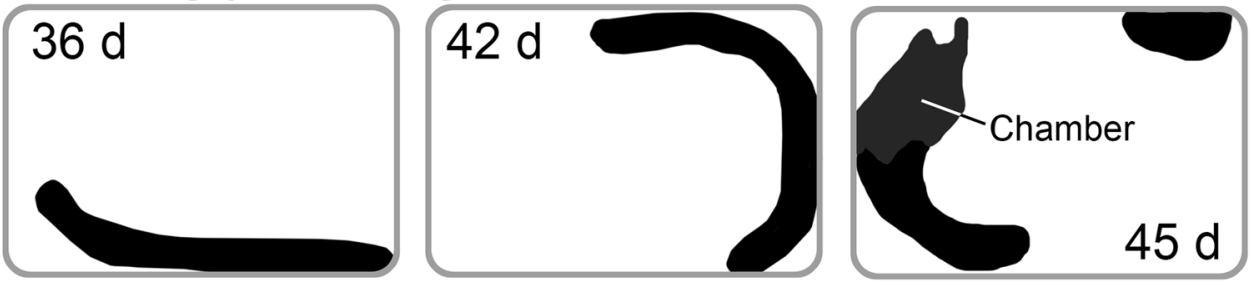

Post-weaning | post-weanlings
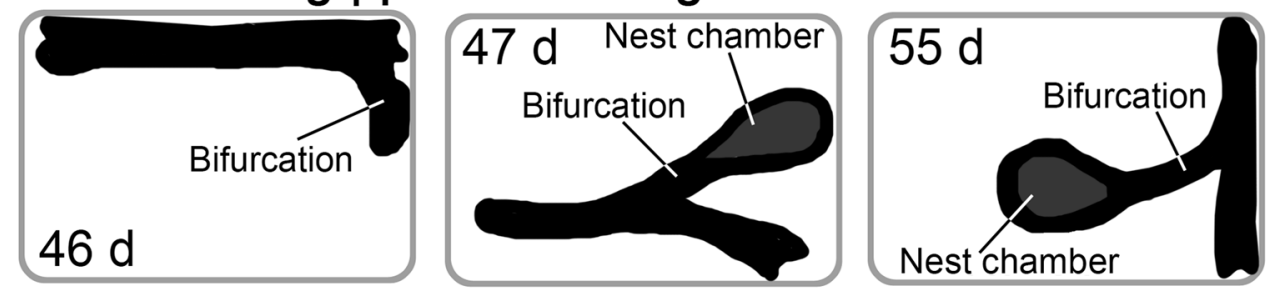

Dispersal age | dispersers

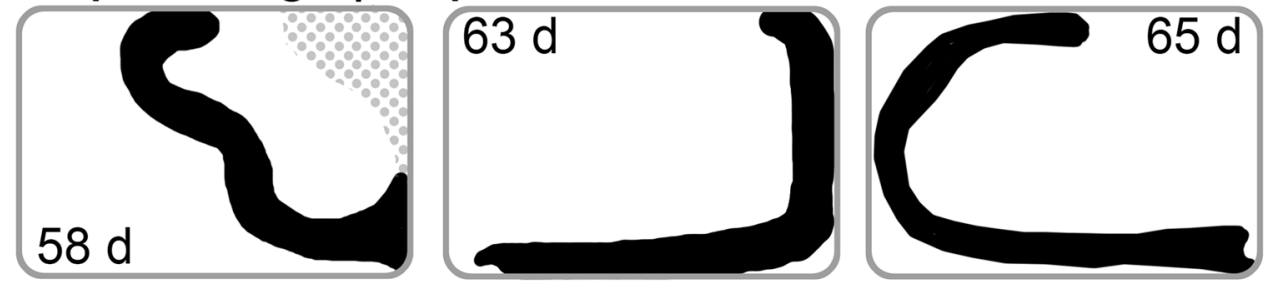


related to scratch-digging are still immature to confer an adequate mechanical performance during digging, which is supported by behavioural data reported here. As for scratch-digging, burrow construction was also expressed early; though a high inter-individual variability was observed: some individuals were able to dig their first burrow (and then shelter into it) during lactancy (Fig. 7) while others started during post-weaning. Again, although morphological evidence suggests that pups may have the mechanical ability to disaggregate the substrate (Echeverría et al. 2014), the ability to build functional burrow systems-i.e., main tunnel, foraging tunnels, and nest present-may require a maturation period of approximately 45-60 days, i.e., after weaning.

Motor behaviours displayed during tunnel digging by adults were also observed in very young individuals. For example, pups were capable of loosening the soil with rapid strokes on the soil by alternating movements of foreclaws, and ejecting it backwards using their large hindfeet when accumulated under their abdomen (a rare behaviour in subterranean mammals, but present in ctenomyids, and shared with most bathyergids; Hickman 1985; Fig. 7). As for scratch-digging, these behaviours were expressed during lactancy in the absence of either a burrowing demonstrator or an early subterranean environment (the natal burrow). On the other hand, it was not until animals were close to weaning that they moved backwards from the surface to the tunnel entrance (Fig. 7), a behaviour that may be of great relevance not only during burrow construction (e.g., saving energy by constructing tunnels not much larger than the size of the animal and avoiding the need to turn around inside the tunnel after digging), but also during agonistic encounters (e.g., as part of an offensive attack or defensively evading the opponent; Zenuto et al. 2002b; Echeverría 2011), or when foraging aboveground (e.g., reducing the risk of predation by quickly returning to the safety of the burrow while scanning the surrounds). In mole rats, for instance, Eilam et al. (1995) have observed that individuals moving uphill preferred to go backwards using plantigrade foot postures, presumably to prevent sliding. Uphill backward locomotion also allows animals to cope with changes in weight distribution between the hind and forelimbs without modifying footfall pattern relative to the direction of progression. However, further research is required to determine the preferred locomotor behaviour according to substrate characteristics in ctenomyids.

Another ecologically relevant behaviour observed in young individuals was the rearing posture, which represent a limited, non-locomotory, bipedalism (bipedal stance) by standing on hind legs to survey the surroundings, without bipedally walking. Standing posture is unusual for subterranean mammals which achieve overground movements through a quadrupedal posture, probably because of the lack of the required equilibrium or strength for such posture. During rearing exploration, animals must be able to maintain standing posture and equilibrium, which is accomplished by using the postural muscles of the trunk and limbs (Muir 2000). In C. talarum, the onset of this posture took place between lactancy and post-weaning, suggesting the existence of a high inter-individual variability in the development of postural muscles and/or neural controlling mechanisms. Particularly, we observed it more frequently in older animals, reflecting it as an agedependent behaviour. Rearing occurs in several non-phylogenetic related groups of small mammals (e.g. meerkats Suricata suricatta, rats Rattus sp., mice Mus musculus), rodents which perform both burrowing and surface activities (e.g. black-tailed prairie dogs Cynomys ludovicianus, desert cavies Microcavia australis, and degus Octodon
Fig. 7 Postnatal ontogeny of salient behaviours related to scratch-digging in Ctenomys talarum (modified from Echeverría 2011)

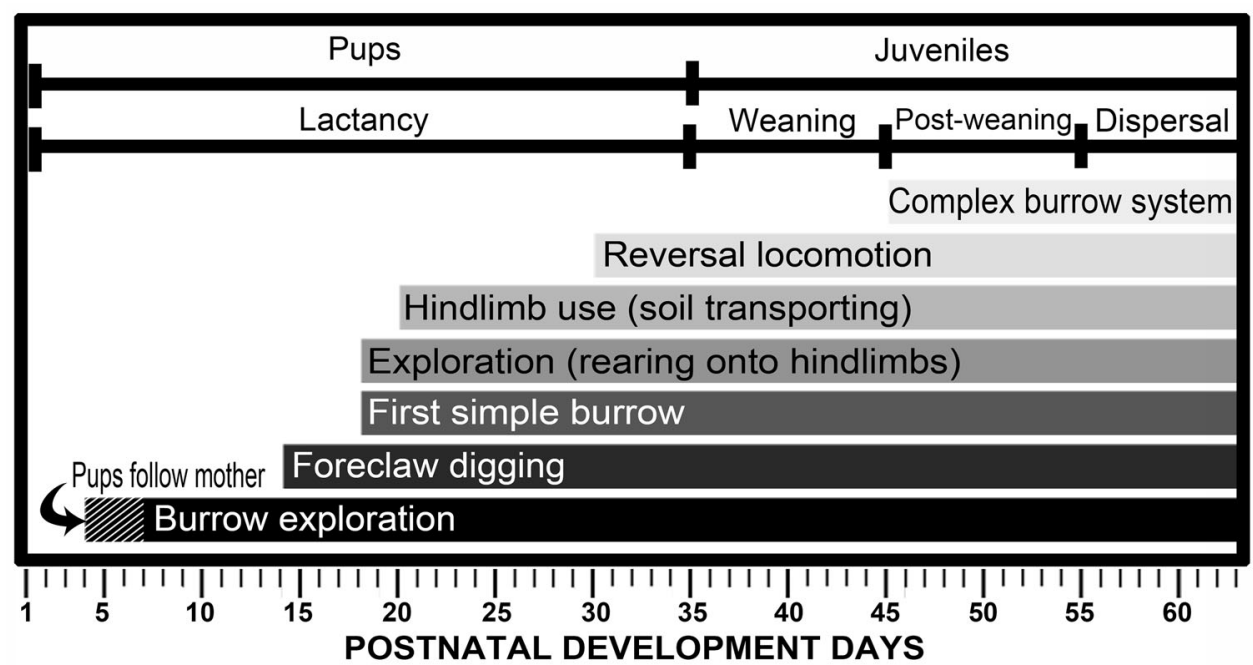


degus) and even adults of closely related species to $C$. talarum [e.g. C. opimus (Pearson 1959), C. fulvus (Hickman 1985), C. mendocinus (Camín et al. 1995) and $C$. magellanicus (AIV, pers. obs.)]. Although this behaviour is not directly related to burrowing, rearing upon exiting the burrow enhances predator and food detection. This increases the animal's confidence in moving further away from the burrow. For example, Camín et al. (1995) have observed cut-off stems of bushes, grasses and cacti around the burrow entrances of $C$. mendocinus burrow systems, and $C$. magellanicus has been observed cutting bush stems in a bipedal stance (AIV, pers. obs.). Clearly, standing posture is a relevant behaviour when foraging overground. Conversely, the more specialized subterranean rodent-the naked mole rat Nanospalax - only pokes its body at the feeding openings; which contrast with the relatively longer travels looking for food made by tuco-tucos (e.g., from $50 \mathrm{~cm}$ to a few meters, C. talarum and C. australis, respectively).

Taking into account that (a) some anatomical adaptations for scratch-digging are already present in very young individuals and others develop progressively (Echeverría et al. 2014), (b) subterranean lifestyle is assumed to be highly costly due to the high energetic demand of tunnel extension (Vleck 1979; Luna et al. 2002), and (c) C. talarum displays a long maternal care period ( $\sim 2$ months; Zenuto et al. 2002a), the early occurrence of scratch-digging and burrow construction would provide of enough time to reach a proper musculoskeletal and behavioural development, mainly to deal with energetic and biomechanical demands. Some authors argued that juvenile mammals locomote more, compared to adults, for thermorregulation or locomotor training (Bayers and Walker 1995). For example, it is known that physical activity promotes a normal development of muscles and bones (e.g., Herring and Lakars 1981) due to pleiotropic relationships and epigenetic effects between them (Young et al. 2009; and references therein). Epigenetic effects of the early biomechanical environment have been documented in several groups of mammals and, therefore, it is widely accepted that both genetic and epigenetic factors determine the final shape and strength of the skeleton (Carter et al. 1998; Nowlan and Prendergast 2005). Herring and Teng (2000) have shown that, within mammals, patterns of muscle contractions (e.g., muscle exercise) are related to strains on the bones, and this interaction between muscle and bone can cause a differential growth in those areas that are closest to peak strains (Young et al. 2009; and references therein). These facts suggest that morphological and behavioural ontogenies in $C$. talarum probably interact with each other and the postnatal period ( $\sim 2$ months) might be of great relevance not only for practicing the construction of burrow systems, but also to achieve through body exercise the appropriate musculoskeletal development, effectiveness and/or efficiency for such behaviour (e.g., a repeated early digging activity may positively affect the development of humeri resistance to bend or favour epicondylar growth in diameter). In fact, we observed that most of changes at the behavioural level, occur between the ages of lactancy and weaning (e.g., more complex burrows, longer tunnels, longer time dedicated to digging activities) and at the dispersing age, when all individuals were able to dig a burrow system (e.g. main tunnel, nest chamber, foraging branches, and burrow openings; Antinuchi and Busch 1992), along with the maturation of morphological specializations of the species (see Echeverría et al. 2014).

Acknowledgments We are grateful to all members of the Physiological and Behavioral Ecology Lab (Universidad Nacional de Mar del Plata, Argentina), for their constant support and advice. This work was supported by the Consejo Nacional de Investigaciones Científicas y Técnicas [PIP 1380 (2009-2011)]; the Agencia Nacional de Promoción Científica [PICT 2010-2121-BID 1728/OC-AR]; the Ministerio de Ciencia e Innovación de España [CGL2011-23919; Estudio alométrico y funcional de la capacidad excavadora en Ctenomys (Mammalia: Rodentia)]; and the Universidad Nacional de Mar del Plata (15/E340 EXA392/08). AIE was supported by a Consejo Nacional de Investigaciones Científicas y Técnicas fellowship.

\section{References}

Antinuchi CD, Busch C (1992) Burrow structure in the subterranean rodent Ctenomys talarum. Z Säugetierkunde 57:163-168

Antinuchi CD, Zenuto RR, Luna F, Cutrera AP, Perisinotti P, Busch C (2007) Energy budget in subterranean rodents: insights from the tuco-tuco Ctenomys talarum (Rodentia: Ctenomyidae). In: Kelt DA, Lessa E, Salazar-Bravo JA, Patton JL (eds) The quintessential naturalist: honoring the life and legacy of Oliver $\mathrm{P}$. Pearson. University of California Publications in Zoology, Berkeley, pp 111-140

Bates D, Machler M, Bolker B (2011) lme4: linear mixed-effects models using s4 classes. http://cran.R-project.org/package=lme4. $\mathrm{R}$ package version $0.999375-42$

Bayers JA, Walker C (1995) Refining the motor training hypothesis for the evolution of play. Am Nat 146:25-40

Busch C, Malizia AI, Scaglia OA, Reig OA (1989) Spatial distribution and attributes of a population of Ctenomys talarum (Rodentia: Octodontidae). J Mammal 70:204-208

Camín SR, Madoery LA, Roig V (1995) The burrowing behaviour of Ctenomys mendocinus (Rodentia). Mammalia 59:9-17

Carter D, Mikic B, Padian K (1998) Epigenetic mechanical factors in the evolution of long bone epiphyses. Zool J Linnean Soc 123:163-178

Comparatore VM, Busch C, Cid MS (1995) Dietary preferences of two sympatric subterranean rodents population in Argentina. Rev Chil Hist Nat 68:197-206

Crawley MJ (2007) The R Book. Wiley, Chichester

Conour LA, Murray KA, Brown MJ (2006) Preparation of animals for research-issues to consider for rodents and rabbits. ILAR J 47(4):283-293

Cutrera AP, Antinuchi CD, Busch C (2003) Thermoregulatory development in pups of the subterranean rodent Ctenomys talarum. Physiol Behav 79:321-330 
Cutrera AP, Antinuchi CD, Mora MS, Vassallo AI (2006) Homerange and activity patterns of the south american subterranean rodent Ctenomys talarum. J Mammal 87(6):1183-1191

del Valle JC, Lohfely MI, Comparatore VM, Cid MS, Busch C (2001) Feeding selectivity and food preference of Ctenomys talarum (tuco-tuco). Mamm Biol 66:165-173

Ebensperger LA, Blumstein DT (2006) Sociality in New World hystricognath rodents is linked to predators and burrow digging. Behav Ecol 17:410-418

Echeverría AI (2011) Ontogenia del comportamiento en el roedor subterráaneo Ctenomys talarum (Rodentia: Ctenomyidae). $\mathrm{PhD}$ dissertation, Mar del Plata, Bs. As., University of Mar del Plata, Argentina

Echeverría AI, Becerra F, Vassallo AI (2014) Postanatal ontogeny of limb proportions and functional indices in the subterranean rodent Ctenomys talarum (Rodentia, Ctenomyidae). J Morphol 275(8):902-913

Eilam D (1997) Postnatal development of body architecture and gait in several rodent species. J Exp Biol 200:1339-1350

Eilam D, Adijes M, Vilensky J (1995) Uphill locomotion in mole rats: a possible advantage of backward locomotion. Physiol Behav 58(3):483-489

Ellison GTH (1995) Is nest building an important component of thermoregulatory behaviour in the pouched mouse (Saccostomus campestris). Physiol Behav 57:693-697

Fabre PH, Galewski T, Tilak M, Douzery EJP (2013) Diversification of South American spiny rats (Echimyidae): a multi-gene phylogenetic approach. Zool Scr 42:117-134

Fernández ME, Vassallo AI, Zárate M (2000) Functional morphology and paleobiology of the Pliocene rodent Actenomys (Caviomorpha: Octodontidae): the evolution to a subterranean mode of life. Biol J Linn Soc 71:71-90

Fleming TH, Brown GJ (1975) An experimental analysis of seed hoarding and burrowing behaviour in two species of Costa Rican heteromyid rodents. J Mammal 56:301-315

Giannoni SM, Borghi CE, Roig VG (1996) The burrowing behavior of Ctenomys eremophilus (Rodentia, Ctenomyidae) in relation with substrate hardness. Mastoz Neotr 3(2):161-170

Herring SW, Lakars TC (1981) Craniofacial development in the absence of muscle contraction. J Cran Genet Dev Biol 1:341-357

Herring SW, Teng S (2000) Strain in the braincase and its sutures during function. Am J Phys Anthropol 112:575-593

Heth G (1989) Burrow patterns of the mole rat Nannospalax ehrenbergi in two soil types (terra rossa and rendzina) in Mount Carmel. Israel J Zool 7:39-56

Hildebrand M (1985) Digging of quadrupeds. In: Hildebrand M, Bramble DM, Liem KF, Wake DB (eds) Functional vertebrate morphology. Belknap, Cambridge, pp 89-109

Hickman GC (1985) Surface-mound formation by the tuco-tuco, Ctenomys fulvus (Rodentia: Ctenomyidae), with comments on earthpushing in other fossorial mammals. J Zool Lond 205:385-390

Kinlaw A (1999) A review of burrowing by semi-fossorial vertebrates in arid environments. J Arid Environ 41:127-145

Kirkton SD, Harrison JF (2006) Ontogeny of locomotory behaviour in the American locust, Schistocerca americana: from marathoner to broad jumper. Anim Behav 71:925-931

Lessa EP, Vassallo AI, Verzi DH, Mora MS (2008) Evolution of morphological adaptations for digging in living and extinct ctenomyid and octodontid rodents. Biol J Linn Soc 95:267-283

Lacey E, Patton JL, Cameron GN (2000) Life Underground: The Biology of Subterranean Rodents. Chicago Uni- versity Press, Chicago, p 449p

Luna F, Antinuchi CD, Busch C (2002) Digging energetics in the South American rodent Ctenomys talarum (Rodentia, Ctenomyidae). Can J Zool 80:2144-2149
Malizia AI, Busch C (1991) Reproductive parameters and growth in the fossorial rodent Ctenomys talarum (Rodentia: Octodontidae). Mammalia 55:293-305

Mares MA, Ojeda RA (1982) Patterns of diversity and adaptation in South American hystricognath rodents. In: Mares MA, Genoways HH (eds) Mammalian Biology in South America. Special Publication Series, Pymatuning Laboratory of Ecology, University of Pittsburgh, Pittsburgh, pp 393-432

Mora MS, Olivares AI, Vassallo AI (2003) Size, shape and structural versatily of the skull of the subterranean rodent Ctenomys: functional morphological analysis. Biol J Linn Soc 78:85-96

Morgan CC (2009) Geometric morphometrics of the scapula of South American caviomorph rodents (Rodentia: Hystricognathi): form, function and phylogeny. Mamm Biol 74:497-506

Morgan CC, Verzi DH (2006) Morphological diversity of the humerus of the South American subterranean rodent Ctenomys (Rodentia, Ctenomyidae). J Mammal 87:1252-1260

Muir GD (2000) Early ontogeny of locomotor behaviour: a comparison between altricial and precocial animals. Brain Res Bull 53(5):719-726

Nevo E (1999) Mosaic Evolution of Subterranean Mammals. Oxford UP, Oxford

Nowlan NC, Prendergast PJ (2005) Evolution of mechanoregulation of bone growth will lead to non-optimal bone phenotypes. J Theor Biol 235:408-418

Parada A, D’Elía G, Bidau CJ, Lessa EP (2011) Species groups and the evolutionary diversification of tuco-tucos, genus Ctenomys (Rodentia: Ctenomyidae). J Mammal 92:671-682

Pearson OP (1959) Biology of the subterranean rodents, Ctenomys in Perú. Mem Mus Hist Nat Javier Prado 9:1-55

Pinheiro JC, Bates DM (2000) Mixed-effects models in S and S-PLUS. Springer, Berlin

Pinheiro JC, Bates DM, DebRoy S, Sarkar D, R Development Core Team (2011) nlme: linear and nonlinear mixed effects models. $\mathrm{R}$ package version 3.1-102

R Development Core Team (2012) R: a language and environment for statistical computing. R Foundation for Statistical Computing, Vienna. ISBN 3-900051-07-0. http://www.R-project.org

Reig OA, Busch C, Ortells MO, Contreras JR (1990) An overview of evolution, systematics, population biology, cytogenetics, molecular biology and speciation in Ctenomys. In: Nevo E, Reig OA (eds) Evolution of Subterranean Mammals at the Organismal and Molecular Levels. Alan R. Liss, New York, pp 71-96

Stamps J (2003) Behavioural processes affecting development: Tinbergen's fourth question comes of age. Anim Behav 66:1-13

Trillmich F, Bieneck M, Geissler E, Bischof H-J (2003) Ontogeny of running performance in the wild guinea pig (Cavia aperea). Mamm Biol 68(4):214-223

Tuli JS, Smith JA, Morton DB (1995) Stress measurements in mice after transportation. Lab Anim 29:132-138

Vassallo AI (1998) Functional morphology, comparative behaviour, and adaptation in two sympatric subterranean rodents genus Ctenomys (Caviomorpha: Octodontidae). J Zool 244:415-427

Vassallo AI (2006) Acquisition of subterranean habits in tuco-tucos (Rodentia, Caviomorpha, Ctenomys): role of social transmission. J Mammal 87(5):939-943

Vassallo AI, Antenucci CD (2015) Biology of caviomorph rodents: diversity and evolution. Sociedad Argentina para el Estudio de los Mamíferos (SAREM), Mendoza, p 338. ISBN 978-98798497-3-6

Verzi DH (2008) Phylogeny and adaptive diversity of rodents of the family Ctenomyidae (Caviomorpha): delimiting lineages and genera in the fossil record. J Zool 274(4):386-394

Vleck D (1979) The energy cost of burrowing by the pocket gopher Thomomys bottae. Physiol Zool 52:122-135 
Whitford WG, Kay RF (1999) Bioperturbation by mammals in deserts: a review. J Arid Environ 41:203-230

Wiedenmayer C (1997) Stereotypies resulting from a deviation in the ontogenetic development of gerbils. Behav Proc 39(3):215-221

Young NM, Hallgrímsson B, Garland T Jr (2009) Epigenetic effects on integration of limb lengths in a mouse model: selective breeding for high voluntary locomotor activity. Evol Biol 36:88-99

Zelová J, Šumbera R, Okrouhlík J, Burda H (2010) Cost of digging is determined by intrinsic factors rather than by substrate quality in two subterranean rodent species. Physiol Behav 99(1):54-58
Zenuto RR, Antinuchi CD, Busch C (2002a) Bioenergetics of reproduction and pup development in a subterranean rodent (Ctenomys talarum). Physiol Biochem Zool 75:469-478

Zenuto RR, Vassallo AI, Busch C (2002b) Comportamiento social y reproductivo del roedor subterráneo solitario Ctenomys talarum (Rodentia: Ctenomyidae) en condiciones de semicautiverio. Rev Chil Hist Nat 75:165-177 